\title{
Model Kinerja Pegawai: Kepemimpinan, Budaya Kerja, dan Motivasi Kerja dengan Kepuasan kerja variabel intervening
}

\author{
Gusni Ami Jayanti, Nazwirman* \\ Magister Manajemen Universitas Yarsi, Jakarta \\ Jl Letjen Suprapto, Cempaka Putih, Jakarta Pusat, Indonesia \\ *Koresponden: nazwirman@yarsi.ac.id
}

\section{Artikel Info \\ Received: \\ 12 Mei 2020 \\ Revised: \\ 27 Agustus 2020 \\ Accepted: \\ 30 Oktober 2020}

Published by Jurnal Ilmiah Manajemen dan Bisnis, Indonesia Copyright (C) 2020 by the Author(s) | This is an open access article distributed under the Creative Commons Attribution License

http://creativecommons.org/licenses /by/4.0), which

permitsunrestricted use, distribution, and reproduction in any medium, provided the original work is properly cited.

\begin{abstract}
ABSTRAK
Penelitian bertujuan untuk menganalisis dan mendiskripsikan pengaruh Variabel Kepemimpinan, Budaya Kerja, Motivasi Kerja, Kepuasan Kerja tarhadap Variabel Kepuasan Kerja dan Variabel Kinerja pada Satuan Tugas Waspada Investasi (SWI) Otoritas Jasa Keuangan. Sampel sebanyak 100 yang seluruhnya dianalisis menggunakan SEM (Structural Equation Model) dengan perangkat lunak SmartPLS. Hasil penelitian menunjukan bahwa Kepemimpinan berpengaruh langsung signifikan positif terhadap Kepuasan kerja. Kepemimpinan berpengaruh signifikan positif terhadap Kinerja. Budaya Kerja berpengaruh signifikan positif terhadap Kepuasan Kerja. Budaya Kerja berpengaruh signifikan positif terhadap Kinerja. Motivasi Kerja berpengaruh signifikan positif terhadap Kepuasan Kerja. Motivasi Kerja berpengaruh signifikan positif terhadap Kinerja. Kepuasan kerja berpengaruh signifikan positif terhadap Kinerja Satgas Waspada Investasi. Kepuasan Kerja mampu memediasi pada Kepemimpinan terhadap Kinerja. Kepuasan Kerja mampu memediasi pada Budaya Kerja terhadap Kinerja. Kepuasan Kerja mampu memediasi pada Motivasi Kerja terhadap Kinerja. Upaya meningkatkan kinerja pegawai Satuan Tugas Waspada Investasi pihak otorias jasa keuangan perlu mempertimbangkan keempat veriabel yang mempengaruhinya.
\end{abstract}

Kata Kunci: Kepemimpinan, Budaya Kerja, Motivasi Kerja, Kepuasan Kerja, Kinerja, SWI

\section{Employee Performance Model: Leadership, Work Culture, and Work Motivation with job satisfaction as Intervening variable}

\begin{abstract}
The research aims to analyze and describe the influence of Leadership Variables, Work Culture, Work Motivation, Job Satisfaction towards Job Satisfaction Variables and Performance Variables on the Investment Alert Task Force of the Financial Services Authority. A total of 100 samples were analyzed using SEM (Structural Equation Model) with SmartPLS software. The results showed that leadership had a significant positive direct effect on job satisfaction. Leadership has a significant positive effect on performance. Work Culture has a significant positive effect on Job Satisfaction. Work Culture has a significant positive effect on performance. Work motivation has a significant positive effect on job satisfaction. Work motivation has a significant positive effect on performance. Job satisfaction has a significant positive effect on the performance of the Investment Alert Task Force. Job Satisfaction is able to mediate on Leadership on Performance. Job Satisfaction is able to mediate the Work Culture of Performance. Job Satisfaction is able to mediate on Work Motivation on Performance. Efforts to improve the performance of the Investment Alert Task Force employees of the financial services authority need to consider the four variables that influence it.
\end{abstract}

Keywords: Leadership, Work Culture, Work Motivation, Job Satisfaction, Performance, Investment

DOI: $h$ htps://doi.org/10.30596/jimb.v21i2.4582

JEL CLASSIFICATION: O, O1, 015

Cara Sitasi :

Jayanti, G.A., Nazwirman" , A. S. . (2020). Model Kinerja Pegawai: Kepemimpinan, Budaya Kerja, dan Motivasi Kerja dengan Kepuasan kerja variabel intervening. Jurnal Ilmiah Manajemen dan Bisnis, 21(2), 157-173. https://doi.org/10.30596/jimb.v21i2.4582. 


\section{PENDAHULUAN}

Dibentuknya Otoritas Jasa Keuangan (OJK) bertujuan agar kegiatan di dalam sektor jasa keuangan terselenggaranya tata kelola yang baik (good governance), untuk mewujudkan sistem keuangan tumbuh secara suistinable, stabil serta mampu melindungi kepentingan masyarakat. Salah satu tugas pokok bidang manajemen strategis OJK adalah mengkoordinasi pelaksanaan penyidikan. Pendelegasian pelaksanaan tugas ini dilakukan pada Departemen Penyidikan sektor Jasa Keuangan (DPJK) di bawah koordinasi Deputi Komisioner Manajemen Strategis (https://www.ojk.go.id/). Keterlibatan OJK dalam Satuan Tugas Waspada Investasi (SWI) yaitu untuk mewujudkan koordinasi yang efektif antar instansi pengawas di bidang penghimpunan dana masyarakat dan pengelolaan investasi serta dengan aparat penegak hukum lainnya, regulator, instansi pengawas, dan penegak hukum membentuk SWI melalui Surat Keputusan Ketua Bapepam-LK Nomor Kep-208/BL/2007 tanggal 20 Juni 2007. SWI dalam menangani masalah investasi memiliki jumlah sebanyak 116 personal.

Setiap kegiatan investasi yang dilakukan ditengah masyarakat sangat dimungkinkan berpotensi risiko seperti terjadi investasi "bodong" yang dapat merugikan banyak pihak. Untuk menanggulangi keadaan ini diperlukan sumber daya yang mampu mengerahkan keahliannya secara maksimal. Namun hal ini sangat dipengaruhi beberapa factor diantaranya kemampuan pemimpin (Zigarmi \& Roberts, 2017; Altmäe et al., 2013) untuk mengelola atau mengkoordinasikan bawahan dan menciptakan budaya kerja yang baik (Ahmad; 2018, Samosir, 2018), memotivasi pegawai sehingga mereka puas terhadap apa yang dilakukan yang berakibat pada kinerja (Rahman et al., 2019; Inuwa, 2016).

Dalam penelitian sebelumnya terhadap kinerja SWI masih belum banyak dilakukan. Ini disebabkan akses masuk objek untuk diteliti cukup sulit. Keterbatasan jumlah personil dan luasnya wilayah yang menjadi bagian masalah yang dihadapi SWI dalam melakukan tugas mereka. Namun tidak berarti keterbatasan ini para pegawai memiliki kinerja kurang baik. Oleh karena itu penelitian secara komprehensif bertujuan menganalisis dan mendeskripsikan variabelvariabel yang mempengaruhi kinerja SWI.

Fungsi pemimpin sebagai pemberi arahan, komando, dan pengambil keputusan (Northouse, 2007; Yukl, 2013). Bentuk dominasi yang didasari atas kemampuan pribadi yang sanggup mendorong atau mengajak orang lain untuk berbuat sesuatu yang berdasarkan penerimaan oleh kelompoknya (Nazwirman, 2020). Pemimpin yang baik adalah berasal dari orang yang memiliki kepribadian baik pula (good leader is good person) (Sunny et al., 2019). Proses dalam pemimpin atau disebut kepemimpinan mencakup tiga elemen yaitu konsep relasi, proses melakukan sesuatu, dan membujuk orang lain untuk mengambil tindakan (Bass, 1999). Fungsi kepemimpinan mencakup perencanaan, pemrakarsaan, pengendalian, pendukung, penginformasian, pengevaluasiaan (Santos et al., 2015). Dimensi kepemimpinan ada 4 (empat) dengan konsep "4I" (Jalal et al., 2012) yaitu (1) Idealized influence, sebagai perilaku yang menghasilkan rasa hormat (respect) dan rasa percaya diri (trust) dari orang-orang yang dipimpinnya. (2) Inspirational motivation, perilaku yang senantiasa menyediakan tantangan dan makna atas pekerjaan orang-orang yang dipimpin. (3) Intellectual simulation. mendemonstrasikan tipe kepemimpinan yang senantiasa menggali ide-ide baru dan solusi kreatif dari orang-orang yang dipimpinnya. (4) Individualized consideration, yang direfleksikan selalu mendengarkan dengan penuh perhatian, dan memberikan perhatian khusus kepada kebutuhan prestasi dan kebutuhan dari orang-orang yang dipimpinnya. Selain itu kepemimpinan memiliki beberapa peranan (role) yaitu: (1) Peranan yang bersifat interpersonal (2) Peranan yang bersifat informasional, dan (3) Peranan pengambilan keputusan (Mintzber, 2010).

Secara praktis budaya kerja bermakna dari pola nilai, sikap, perilaku, niat dan hasil pekerjaan, termasuk instrumen, sistem kerja, teknologi dan bahasa yang digunakan yang di 
tanamkan secara terus menerus sehingga membentuk sebuah budaya kerja yang nantinya di harapkan dapat memajukan kinerja perusahaan (Ghazi \& Muzaffar, 2018; Rajendar \& Jun, 2005).

Schein (2014) melaporkan budaya kerja merupakan suatu pola asumsi dasar yang diciptakan, ditemukan, atau dikembangkan oleh kelompok tertentu sebagai pembelajaran untuk mengatasi masalah adaptasi eksternal dan integrasi internal yang terjadi dalam perusahaan. Dalam proses budaya terdapat saling memengaruhi dan saling ketergantungan (interdepensi), baik sosial maupun lingkungan sosial (Mustanir \& Rusdi, 2019). Budaya kerja akan menjadi kenyataan melalui proses panjang, karena perubahan nilai-nilai lama menjadi nilai-nilai baru akan memakan waktu untuk menjadi kebiasaan dan terus melakukan penyempurnaan dan perbaikan serta meyelesaikan pekerjaan tepat waktu sesuai dengan rencana (Sinha et al., 2010). Khuzaeni et al., (2013) mengkategorikan lapisan budaya untuk mengklasifikasikan orang berdasarkan kebiasaan lingkungan mereka: tingkat nasional, tingkat lokal, perbedaan tingkat jenis kelamin, tingkat generasi, tingkat sosial, dan tingkat organisasi atau perusahaan. Perilaku kerja seseorang secara langsung atau tidak langsung dipengaruhi oleh nilai budaya organisasi yang dimanifestasikan ke dalam budaya kerja (Rajendar \& Jun, 2005).

Motivasi kerja merupakan suatu rangkaian keadaan dalam diri seseorang yang mendorong atau menggerakan keinginan individu untuk melakukan kegiatan-kegiatan yang berkaitan dengan kerja tertentu (Uzonna, 2013). Pemberian motivasi sangat penting dalam setiap perusahaan, sebab motivasi yang ada dalam diri seseorang akan mewujudkan suatu perilaku yang diarahkan pada tujuan yang mencapai sasaran kepuasan dan mempengaruhi kinerja seseorang (Gachengo \& Wekesa, 2017)

Pegawai yang mempunyai motivasi kerja yang tinggi akan dapat mendorong karyawan tersebut bekerja lebih semangat serta dapat memberikan kontribusi positif terhadap pekerjaan yang telah menjadi tanggung jawabnya. Motivasi berkaitan dengan tingkat usaha yang dilakukan oleh seseorang dalam mengejar suatu tujuan motivasi berkaitan erat dengan kepuasan pekerja dan performansi pekerjaan (Nabi et al., 2017).

Motivasi pegawai diperlukan sebagai daya pengerak yang menciptakan kegairahan kerja kerja SWI. Motivasi agar mau bekerja sama, bekerja efektif dan terintegrasi dengan segala daya upayanya untuk mencapai kepuasan (Rahman et al., 2019). Kepuasan Kerja sebagai sikap positif pegawai terhadap pekerjaannya yang timbul berdasarkan penilaian terhadap situasi kerja. Dengan adanya motivasi pegawai, maka kebutuhannya akan terpenuhi, sehingga akan timbul kepuasan kerja yang berdampak positif pada kinerja pegawai SWI.Kinerja yang dicari oleh perusahaan dari seseorang tergantung dari kemampuan, motivasi, dan dukungan individu yang diterima. Hubungan antara motivasi dan kinerja adalah suatu yang positif, meningkatnya motivasi akan menghasilkan lebih banyak usaha dan prestasi kerja atau kinerja (Robescu \& Iancu, 2016).).

Kepuasan kerja merupakan keadaan emosional, keinginan, kebutuhan, hasrat, dan pengalaman masa lalu atau pengalaman yang menyenangkan dan tidak menyenangkan yang menyatu membentuk harapan kerja (Poon, 2003). Kepuasan kerja (job satisfaction) menunjukan adanya kesesuaian antara harapan seseorang yang timbul dan imbalan yang disediakan oleh pelayanan (Ajis et al., 2020; Farooqui \& Nagendra, 2014).

Tolak ukur kepuasan kerja yang mutlak sulit untuk dicari sebab setiap individu karyawan berbeda standar kepuasannya. Penelitian yang berkaitan dengan kepuasan kerja yang dilakukan oleh (Saari \& Judge, (2004); Garner, (2012) bahwa Kepuasan kerja berpengaruh terhadap produktivitas karyawan. Pada dasarnya bahwa seseorang dalam bekerja akan merasa nyaman dan loyalitas yang tinggi pada perusahaan apabila dalam bekerjanya memperoleh kepuasan kerja sesuai dengan apa yang diinginkan. 
Kinerja mempunyai makna yang lebih luas, bukan hanya hasil kerja, tetapi termasuk bagaimana proses pekerjaan berlangsung termasuk kuantitas, kualitas, dan waktu yang digunakan dalam menjalankan tugas (Robescu \& Iancu, 2016). Kinerja karyawan (Performance employee) merupakan apa yang dilakukan dan tidak dilakukan karyawan yang memengaruhi seberapa banyak mereka memberi kontribusi kepada organisasi, hasil kerja tersebut harus dapat ditunjukkan buktinya secara konkrit dan dapat diukur (Robescu \& Iancu, 2016). Setiap perusahaan harus mampu mengembangkan dan meningkatkan perusahaan dengan mengadakan berbagai cara yang tersusun dalam program untuk meningkatkan kinerja para karyawan (Latif et al., 2019). Berdasarkan hasil telaah tersebut, kerangka pemikiran teoritis yang dikembangkan dalam penelitian ini yaitu:

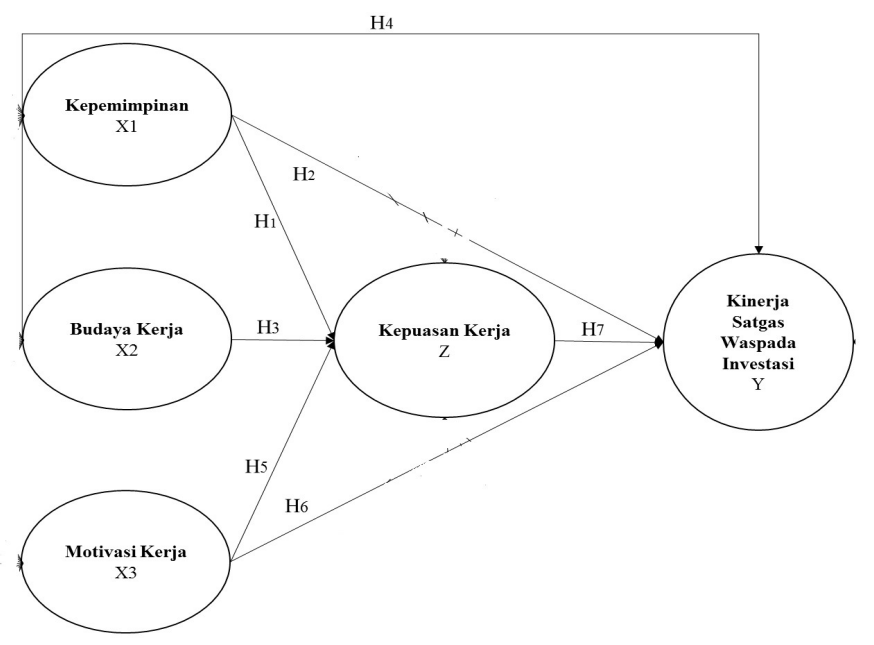

Gambar 1. Model Penelitian

Kepemimpinan dapat memberikan pengaruh kepada bawahan terutama terhadap kepuasan kerja karyawan (Hsiao \& Chen, 2012). Mengingat akan seorang pemimpin dapat memberikan sesuatu yang positif dalam meningkatkan kepuasan kerja karyawan (Choi \& Long, 2014). Studi Choi et al., (2013) memberikan hasil adanya hubungan yang kuat dan signifikan positif antara kepemimpinan dengan kepuasan kerja (Mohammad, 2012). Oleh sebab itu hipotesis penelitian ini yaitu $\mathrm{H}_{1}$ : Kepemimpinan berpengaruh langsung terhadap Kepuasan Kerja

Pemimpin berfungsi sebagai pemberi bermacam arahan, komando, dan pengambilan keputusan (Yukl, 2015; Northouse, 2007). Sanggup mendorong atau mengajak orang lain untuk berbuat sesuatu yang berdasarkan penerimaan oleh kelompoknya (Minzberg 2010). Kinerja merupakan suatu indikator untuk menilai kondisi investasi perusahaan yang dapat diartikan sebagai gambaran, pertumbuhan dan potensi perkembangan yang baik. Faktor pemimpin merupakan factor yang menjadi penentu terhadap kinerja (Susita et al., 2010; Tansel, 2006; Svensson, 2005). Oleh sebab itu hipotesis penelitian ini yaitu $\mathrm{H}_{2}$ : Kepemimpinan berpengaruh langsung terhadap Kinerja

Budaya dapat menjelaskan perbedaan kinerja perusahaan (Heskett, 2012). Setiap budaya unik banyak faktor yang menciptakannya untuk mengatur organisasi (Coleman, 2013). Rentang waktu yang digunakan seorang karyawan di suatu organisasi juga memengaruhi kepuasan kerja. Para karyawan yang lebih lama bekeja dalam suatu organisasi umumnya memiliki tingkat kepuasan yang lebih tinggi (Goris, 2006; Sempane et al., 2002; Agho et al.,1993). Oleh sebab itu 
hipotesis penelitian ini yaitu $\mathrm{H}_{3}$ : Budaya Kerja berpengaruh langsung terhadap variabel Kepuasan Kerja

Budaya kerja merupakan kebiasaan yang dilakukan berulang-ulang oleh karyawan dalam suatu organisasi (MacIntosh \& Doherty, 2010), pelanggaran terhadap kebiasaan ini memang tidak ada sangsi tegas, namun dari pelaku organisasi secara moral telah menyepakati bahwa kebiasaan tersebut merupakan kebiasaan yang harus ditaati dalam rangka pelaksanaan pekerjaan untuk mencapai tujuan (Silverthorne, 2004) dan berpengaruh terhadap kinerja sebagai kualitas dan kuantitas dari suatu hasil kerja (output) individu maupun kelompok (Appealbaoum et al., 2004; Egan et al., 2004; Lund, 2003). Oleh sebab itu hipotesis penelitian ini yaitu $\mathrm{H}_{4}$ : Budaya Kerja berpengaruh langsung terhadap Kinerja

Setiap organisasi yang sukses didukung oleh basis karyawan yang berkomitmen, dan komitmen adalah hasil dari motivasi dan kepuasan kerja (Jeffrey et al., 2011). Ini adalah energi yang mendorong karyawan menuju tujuan organisasi (Nikos et al., 2010). Mustahil bagi organisasi untuk menghasilkan kinerja tanpa komitmen (Tung et al., 2012). Untuk menciptakan keunggulan kompetitif, organisasi perlu memiliki kebijakan dan praktik karyawan yang kompetitif (Maxime et al., 2009). Motivasi mrupakan stimulasi penting yang mengarahkan perilaku manusia (Singh \& Vivek Tiwari, 2011). Tidak ada individu yang memiliki sikap atau perilaku yang sama, maka di tengah-tengah keragaman organisasi ini diharapkan untuk membingkai praktik yang akan dapat memuaskan kelompok dan bukan hanya individu. Organisasi harus mampu mengidentifikasi dan mengevaluasi motivasi yang diperoleh seorang karyawan agar kepuasan kerja lebih lanjut meningkat (Nikos et al., 2010; Fred, 2011; Maxime et al., 2009). Oleh sebab itu hipotesis penelitian ini yaitu $\mathrm{H}_{5}$ : Motivasi Kerja berpengaruh langsung terhadap Kepuasan Kerja.

Motivasi kerja yang tinggi dapat mendorong karyawan bekerja lebih semangat serta dapat memberikan kontribusi positif terhadap pekerjaannya (Naa, 2018). Karyawan ingin mendapatkan gaji dan pembayaran yang masuk akal dan menginginkan pekerjaan yang mereka dapatkan. Uang adalah bujukan mendasar, tidak ada teknik motivasi lain yang mendekati nilai sehubungan nilai yang memperngaruhinya (Kurniawan, 2019). Uang memiliki keunggulan untuk menarik dan memotivasi individu menuju kinerja yang lebih tinggi. Hubungan antara motivasi dan kinerja adalah suatu yang positif, meningkatnya motivasi akan menghasilkan kinerja (Kurniawan, 2019; Permanasari, 2019). Oleh sebab itu hipotesis penelitian ini yaitu $\mathrm{H}_{6}$ : Motivasi Kerja berpengaruh langsung terhadap Kinerja.

Kepuasan kerja mengacu pada sikap umum karyawan terhadap pekerjaannya (Saari \& Judge., 2004). Kepuasan kerja merupakan subyektif individu dari sudut pandang yang mencakup cara karyawan merasa tentang pekerjaannya di organisasi (Garner, 2012; Coombes, 2012). Selain itu, kepuasan kerja adalah keadaan emosional yang menyenangkan yang dihasilkan dari pencapaian nilai-nilai pekerjaan (Coombes, 2012; Vance, 2006). Setiap individu memiliki kriteria yang berbeda untuk mengukur pekerjaan kepuasan (Kim et al., 2017). Penelitian menunjukkan Kepuasan memiliki pengaruh kinerja (Ardhani \& Ratnasari, 2019; Saari \& Judge, 2004; Garner, 2012; Vance, 2006). Oleh sebab itu hipotesis penelitian ini yaitu $\mathrm{H}_{7}$ : Kepuasan Kerja berpengaruh langsung terhadap Kinerja.

\section{METODE}

Populasi dalam penelitian ini adalah pegawai di Departemen Penyidikan Sektor Jasa Keuangan serta pegawai SWI pada OJK. Sedangkan sampel yang digunakan yaitu sampel jenuh yang mengambil seluruh populasi (Hair et al., 2010) pegawai SWI sebanyak 116 orang. Namun proses analisis sampelnyavyang sesuai dan memenuhi kriteria (tidak bias). 
Hompage: http://jurnal.umsu.ac.id/index.php/mbisnis

Variabel penelitian Kepemimpinan (X1), Budaya kerja (X2), Motivasi kerja (X3), Kepuasan kerja (Z) dan Kinerja Satgas Waspada Investasi (Y). Skala pengukuran metode digunakan Likert Scale (Skala Likert) dengan rentang skala 1 (tidak setuju) sampai dengan 5 (sangat setuju).

Alat analisis yang digunakan yaitu Smart Partial Least Square (SmartPLS). SEM dengan PLS terdiri tiga komponen yaitu: model pengukuran atau outer model, model struktural atau inner model, skema pembobotan (weight relation) dan mengukur kecocokan Goodness of Fit (GoF) (Monecke \& Leisch, 2012).

Tabel 1. Kriteria Penilaian Partial Least Square

\begin{tabular}{|c|c|c|}
\hline UJI MODEL & OUTOUT & KRITERIA \\
\hline \multirow[t]{4}{*}{ Outer Model (Uji Indikator) } & Convergensi Validity & $\begin{array}{l}\text { Nilai Loading Factor (LF) } 0,50 \text { - } \\
0,60 \text { sudah dianggap benar }\end{array}$ \\
\hline & Discriminant Validity & $\begin{array}{l}\text { Nilai korelasi cross loading } \\
\text { dengan variable latennya harus } \\
\text { lebih besardibanding dengan } \\
\text { korelasi terhadap variable lainnya }\end{array}$ \\
\hline & $\begin{array}{l}\text { Average Veriance Extracted } \\
\text { (AVE) }\end{array}$ & Nilai AVE nilai arus diatas 0,50 \\
\hline & Composite Reliability & $\begin{array}{l}\text { Nilai composite reliability harus } \\
\text { memiliki nilai } \geq 0,70\end{array}$ \\
\hline \multirow[t]{2}{*}{ Inner Model (Uji hipotesis) } & $\mathrm{R}^{2}$ untuk variable latent endogen & $\begin{array}{l}\text { Hasil } \mathrm{R}^{2} \text { sebesar } 0,67 ; 0,33 ; \text { dan } \\
0,19 \text { mengindikasi bahwa } \\
\text { modelbaik, moderat dan lemah }\end{array}$ \\
\hline & Koefisien parameter dan Tstatistik & $\begin{array}{l}\text { Nilai estimasi untuk hubungan } \\
\text { jalur dalam model structural harus } \\
\text { signifikan, yang dapat diperoleh } \\
\text { dengan prosedur boottrapping }\end{array}$ \\
\hline
\end{tabular}

Sumber: Monecke \& Leisch, (2012).

\section{HASIL DAN PEMBAHASAN}

Berdasarkan skrening yang dilakukan terhadap sampel, terdapat 100 orang sampel yang layak dianalisis. Hasil analisis responden yaitu:

Tabel 2. Karakteristik Responden

\begin{tabular}{|c|c|c|}
\hline Jenis Kelamin & Frekuensi & Persentase \\
\hline Pria & 63 & 63 \\
\hline Wanita & 37 & 37 \\
\hline Jumlah & 100 & 100 \\
\hline \multicolumn{3}{|l|}{ Usia } \\
\hline 20-25 Tahun & 6 & 6 \\
\hline 26-35 Tahun & 33 & 33 \\
\hline 36-45 Tahun & 36 & 36 \\
\hline \multirow[t]{2}{*}{$>45$ Tahun } & 25 & 25 \\
\hline & 100 & 100 \\
\hline \multicolumn{3}{|l|}{ Lama Bekerja } \\
\hline$<1$ Tahun & 4 & 4 \\
\hline 1-5 Tahun & 81 & 84 \\
\hline \multirow[t]{2}{*}{$>5$ Tahun } & 15 & 15 \\
\hline & 100 & 100 \\
\hline
\end{tabular}

Sumber: Olah data output SPSS, (2020) 
Berdasarkan jenis kelamin (Tabel 2) responden berjenis kelamin Pria yaitu sebanyak 63 orang $(63 \%)$ dan berjenis kelamin Wanita yaitu sebanyak 37 orang $(37 \%)$. Hal ini dimungkinkan karena dalam dalam proses penyidikan diperlukan kondisi fisik yang cukup kuat. Usia responden antara 36-45 tahun sebanyak 36 orang (36\%), usia 26-35 tahun sebanyak 33 orang (33\%), Usia $>45$ tahun yaitu sebanyak 25 orang (25\%) dan Usia 20-25 tahun yaitu sebanyak 6 orang (6\%). Usia 26-45 tahun yang merupakan usia yang cukup matang dalam memeroses penyidikan.

Berdasarkan lama bekerja antara 1- 5 tahun yaitu sebanyak 81 orang $(81 \%)$, lama bekerja $>5$ tahun yaitu sebanyak 15 orang $(15 \%)$ dan lama bekerja $<1$ Tahun yaitu sebanyak 4 orang (4\%). Pengalaman yang cukup diperlukan dalam proses penyidikan SWI.

\section{Outer Model}

Tiga kriteria pengukuran digunakan dalam teknik analisis data menggunakan SmartPLS untuk menilai model. Tiga pengukuran itu adalah Convergent validity, Composite reliability, dan Discriminant validity.

Convergent Validity juga dinilai melalui AVE (Average variance extracted). jika suatu model mempunyai nilai AVE diatas 0,5 maka model tersebut dikategorikan mempunyai validitas konvergen (Convergent Validity) yang tinggi (Hair et al., 2010).

Tabel 3. Average Variance Extracted (AVE)

\begin{tabular}{lcccc}
\hline \multicolumn{1}{c}{ Variabel } & $\begin{array}{c}\text { Average Variance Extracted } \\
\text { (AVE) }\end{array}$ & Akar AVE & $\begin{array}{c}\text { Composite } \\
\text { Reliability }\end{array}$ & $\begin{array}{c}\text { Cronbach's } \\
\text { Alpha }\end{array}$ \\
\hline Kepemimpinan & 0.880 & 0.938 & 0.987 & 0.985 \\
Budaya Kerja & 0.854 & 0.924 & 0.983 & 0.981 \\
Motivasi Kerja & 0.838 & 0.916 & 0.981 & 0.978 \\
Kepuasan kerja & 0.853 & 0.923 & 0.983 & 0.981 \\
Kinerja & 0.859 & 0.927 & 0.984 & 0.982 \\
\hline
\end{tabular}

Sumber: data diolah SmartPLS, (2020)

Nilai AVE (Tabel 3) dari setiap konstruk dalam model >0,5. Hasil tersebut menunjukkan bahwa data penelitian memenuhi syarat validitas konvergen (convergent validity). Gabungan dari penilaian dari outer loading dan uji AVE mengindikasikan penelitian ini valid.

Uji reabilitas dilakukan dengan metode Internal consistency. Reliabilitas instrumen penelitian menggunakan Composite Reliability (CR) dan koefisien cronbach's Alpha di atas 0,7. Hasil $C R$ maupun Cronbach Alpha menunjukan seluruh nilai masing-masing variabel diatas nilai 0,7 . Hal tersebut menunjukan konsistensi dan stabilitas instrumen yang digunakan tinggi (handal).

Discriminant validity dapat diukur dengan melihat nilai Cross loading faktor dengan cara membandingkan nilai loading pada konstruk yang dituju harus lebih besar dibandingkan dengan nilai loading konstruk lainnya. Semua indikator mempunyai koefisien korelasi yang lebih besar dengan masing-masing konstruknya dibandingkan dengan nilai koefisien korelasi indikator pada konstruk pada kolom lainnya. Artinya masing-masing indikator dalam konstruk tersebut memiliki nilai discrimant validity yang baik.

\section{Inner Model}

Inner model (inner relation, structural model, dan substantive theory) menggambarkan hubungan antara variabel laten berdasarkan pada teori substantif. Model structural di evaluasi dengan menggunakan $R$-square $\left(\mathrm{R}^{2)}\right.$ untuk konstruk dependen, Stone-Geiser Q-square test untuk predictive relevan.. Semakin tinggi nilai $\mathrm{R}^{2}$ maka semakin besar kemampuan variabel laten 
indipenden dapat menjelaskan variabel laten dependen. Hasil $\mathrm{R}^{2}$ sebesar 0.67 "baik", 0.33 "moderat", dan 0.19 "lemah" (Ghozali, 2014).

Tabel 4. $R$-squared coefficients

\begin{tabular}{c|c}
\hline \multicolumn{1}{c|}{ Variabel } & $\boldsymbol{R}$-Square \\
\hline Kepuasan Kerja & 0.869 \\
Kinerja & 0.936 \\
\hline Sumber: Olah data output SmartPLS, (2020)
\end{tabular}

Nilai R²untuk Kepuasan Kerja sebesar 0.869 (Tabel 4), artinya 86.9\% variasi atau perubahan Kepuasan kerja dipengaruhi oleh Kepemimpinan, Budaya kerja dan Motivasi kerja, sedangkan sebanyak $13.1 \%$ dijelaskan oleh sebab lain. Maka hasil perhitungan $\mathrm{R}^{2}$ termasuk Baik. Nilai $\mathrm{R}^{2}$ Kinerja SWI sebesar 0.936, artinya 93.6\% variasi atau perubahan Kinerja SWI dipengaruhi oleh Kepemimpinan, Budaya kerja, Motivasi kerja dan Kepuasan kerja, sedangkan sebanyak 6.4\% dijelaskan oleh sebab lain. Berdasarkan hal tersebut maka hasil perhitungan menunjukkan bahwa $\mathrm{R}^{2}$ termasuk Baik.

Besaran nilai $Q$-Square $\left(\mathrm{Q}^{2}\right)$ :

$$
\begin{aligned}
\left(\mathrm{Q}^{2}\right) & =1-[(1-\mathrm{R} 21) \times(1-\mathrm{R} 22)]==1-[1-0.869) \times(1-0.936)] \\
& =1-(0.131 \times 0.064)=1-0.0084=0.992
\end{aligned}
$$

$\mathrm{Q}^{2}$ memiliki nilai rentang $0<\mathrm{Q}^{2}<1$, dimana semakin mendekati 1 berarti model semakin baik. Besaran $\mathrm{Q}^{2}$ ini setara dengan koefisien determinasi total pada analisis jalur path (path analysis). Nilai $\mathrm{Q}^{2}>0$ menunjukan model memiliki prediktif relevansi, sebaliknya jika nilai $\mathrm{Q}^{2}$ $\leq 0$ menunjukan model kurang memiliki prediktif relevansi.

Nilai Q-Square sebesar 0.992 menunjukkan bahwa besarnya keragaman data penelitian yang dapat dijelaskan dari penelitian ini adalah sebesar $99.2 \%$ dan sebesar $0.8 \%$ dijelaskan oleh faktor lain di luar penelitian ini. normalan.

Metode bootstrapping terhadap sampel bertujuan untuk meminimalkan masalah ketidak

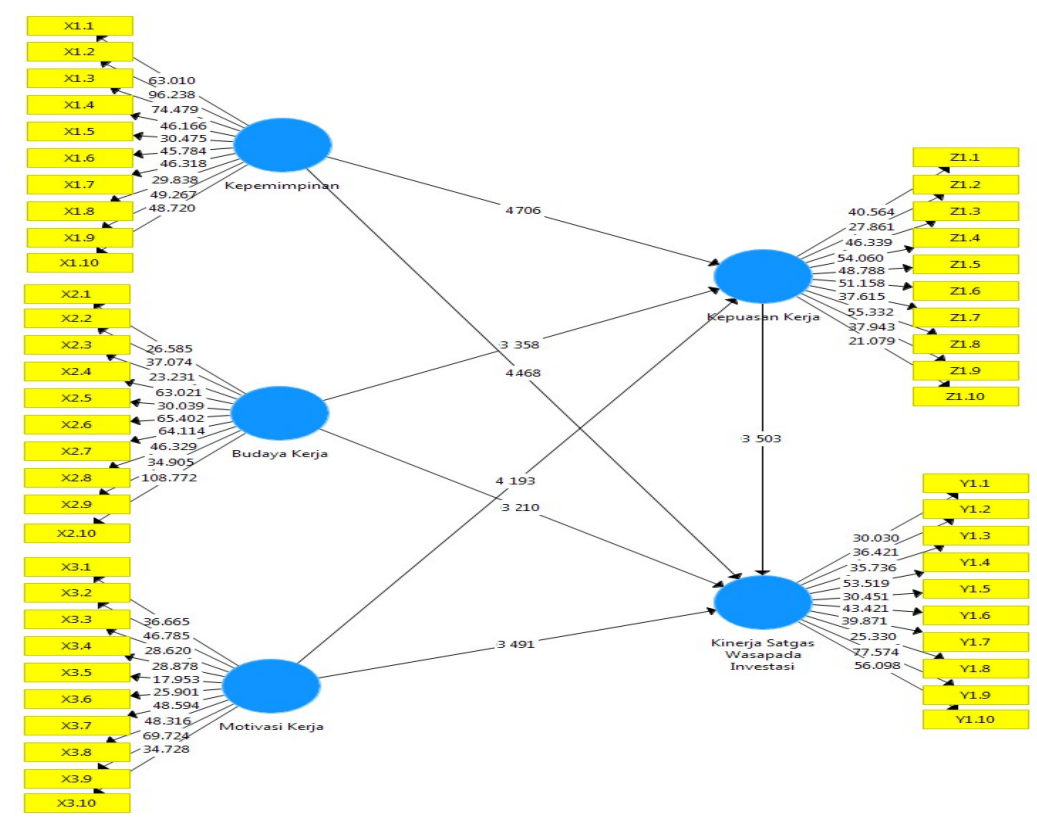

Gambar 1. Model Kinerja Pegawai 
Signifikansi pengaruh variable eksogen terhadap Kinerja SWI melihat nilai koefisien

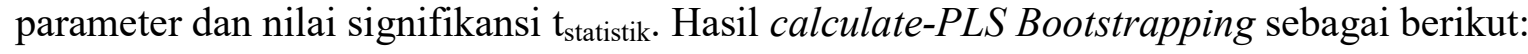

Tabel 5. Hasil Uji Pengaruh Antar Variabel

\begin{tabular}{|c|c|c|c|c|c|c|}
\hline & $\begin{array}{c}\text { Original } \\
\text { Sample } \\
\text { (O) }\end{array}$ & $\begin{array}{c}\text { Sample } \\
\text { Mean } \\
\text { (M) }\end{array}$ & $\begin{array}{l}\text { Standard } \\
\text { Deviation } \\
\text { (STDEV) }\end{array}$ & $\begin{array}{c}\text { T Statistics } \\
(|\mathrm{O} / \mathrm{STDEV}| \\
)\end{array}$ & $\begin{array}{c}\mathbf{P} \\
\text { Values }\end{array}$ & Kesimpulan \\
\hline $\begin{array}{l}\text { Kepemimpinan }(\mathrm{X} 1) \rightarrow \\
\text { Kepuasan Kerja (Z) }\end{array}$ & 0.607 & 0.601 & 0.226 & 4.706 & 0.007 & $\begin{array}{l}\text { Berpengaruh } \\
\text { signifikan }\end{array}$ \\
\hline $\begin{array}{l}\text { Kepemimpinan }(\mathrm{X} 1) \rightarrow \\
\text { Kinerja }(\mathrm{Y})\end{array}$ & 0.099 & 0.084 & 0.209 & 4.468 & 0.006 & $\begin{array}{l}\text { Berpengaruh } \\
\text { signifikan }\end{array}$ \\
\hline $\begin{array}{l}\text { Budaya Kerja (X2) } \rightarrow \\
\text { Kepuasan Kerja (Z) }\end{array}$ & 0.089 & 0.065 & 0.278 & 4.193 & 0.009 & $\begin{array}{l}\text { Berpengaruh } \\
\text { signifikan }\end{array}$ \\
\hline $\begin{array}{l}\text { Budaya Kerja }(\mathrm{X} 2) \rightarrow \\
\text { Kinerja SWI }(\mathrm{Y})\end{array}$ & 0.042 & 0.050 & 0.206 & 3.210 & 0.015 & $\begin{array}{l}\text { Berpengaruh } \\
\text { signifikan }\end{array}$ \\
\hline $\begin{array}{l}\text { Motivasi Kerja (X3) } \rightarrow \\
\text { Kepuasan Kerja (Z) }\end{array}$ & 0.250 & 0.280 & 0.225 & 3.358 & 0.011 & $\begin{array}{l}\text { Berpengaruh } \\
\text { signifikan }\end{array}$ \\
\hline $\begin{array}{l}\text { Motivasi Kerja (X3) } \rightarrow \\
\text { Kinerja SWI (Y) }\end{array}$ & 0.481 & 0.500 & 0.190 & 3.491 & 0.012 & $\begin{array}{l}\text { Berpengaruh } \\
\text { signifikan }\end{array}$ \\
\hline $\begin{array}{l}\text { Kepuasan Kerja }(\mathrm{Z}) \rightarrow \\
\text { Kinerja SWI }(\mathrm{Y})\end{array}$ & 0.370 & 0.358 & 0.248 & 3.503 & 0.010 & $\begin{array}{l}\text { Berpengaruh } \\
\text { signifikan }\end{array}$ \\
\hline
\end{tabular}

Sumber : Data diolah (2020)

Sebagai dasar pengambilan keputusan hipotesis diterima bila nilai $t_{\text {hitung }} \geq t_{\text {tabel }}(1,96)$ dan nilai signifikansi pada $\mathrm{P}$ value $<0,05$. Dari Tabel 5: (1) Kepemimpinan berpengaruh langsung signifikan positif terhadap kepuasan kerja, nilai $t_{\text {hitung }}>t_{\text {tabel }}(4.706>1,96)$ atau $P$ values $<0,05$ $(0,007<0,05)$, sehingga Hipotesis diterima. (2) Kepemimpinan berpengaruh langsung signifikan positif terhadap Kinerja SWI, nilai $\mathrm{t}_{\text {hitung }}<\mathrm{t}$ tabel $(4.139>1,96)$ atau $\mathrm{P}$ values $<0,05(0,009<$ 0,05), sehingga Hipotesis diterima. (3) Budaya Kerja berpengaruh langsung signifikan positif terhadap Kepuasan, nilai $\mathrm{t}$ hitung $<\mathrm{t}$ tabel $(3.358>1,96)$ atau $\mathrm{P}$ values $<0,05(0,011<0,05)$, sehingga Hipotesis diterima. (4) Budaya Kerja berpengaruh langsung signifikan positif terhadap Kinerja, nilai $\mathrm{t}_{\text {hitung }}<\mathrm{t}_{\text {tabel }}(4.468>1,96)$ atau $\mathrm{P}$ values $<0,05(0,006<0,05)$, sehingga Hipotesis diterima.(5) Motivasi Kerja berpengaruh langsung signifikan positif terhadap Kepuasan kerja SWI, nilai $\mathrm{t}_{\text {hitung }}>\mathrm{t}_{\text {tabel }}(3.210>1,96)$ atau $\mathrm{P}$ values $<0,05(0,015<0,05)$, sehingga Hipotesis diterima. (6) Motivasi kerja berpengaruh langsung signifikan positif terhadap Kinerja SWI, nilai $\mathrm{t}_{\text {hitung }}>\mathrm{t}$ tabel $(3.491>1,96)$ atau $\mathrm{P}$ values $<0,05(0,012<0,05)$, sehingga Hipotesis diterima. (7) Kepuasan kerja berpengaruh langsung signifikan positif terhadap Kinerja, nilai $\mathrm{t}$ hitung $>\mathrm{t}$ tabel $(3.503>1,96)$ atau $\mathrm{P}$ values $<0,05(0,010<0,05)$, sehingga Hipotesis diterima.

\section{Tabel 6. Pengaruh Langsung,Tidak Langsung dan Pengaruh Total}

\begin{tabular}{lccc}
\hline \multicolumn{1}{c}{ Variabel Laten } & $\begin{array}{c}\text { Pengaruh } \\
\text { Langsung }\end{array}$ & $\begin{array}{c}\text { Pengaruh Tidak } \\
\text { Langsung }\end{array}$ & Pengaruh Total \\
\hline Kepemimpinan (X1) $\rightarrow$ Kepuasan Kerja (Z) & 0.60 & - \\
Kepemimpinan (X1) $\rightarrow$ Kinerja SWI (Y) & 0.60 & - \\
Budaya Kerja (x2) $\rightarrow$ Kepuasan Kerja (Z) & 0.48 & - \\
Budaya Kerja (X2) $\rightarrow$ Kinerja SWI (Y) & 0.48 & - \\
Motivasi Kerja (X3) $\rightarrow$ Kepuasan Kerja (Z) & 0.25 & - \\
Motivasi Kerja (X3) $\rightarrow$ Kinerja SWI (Y) & 0.41 & \\
Kepuasan Kerja (Z) $\rightarrow$ Kinerja SWI (Y) & 0.37 & $0.60 \times 0.37=$ & $0.222+0.60=0.822$ \\
Kepemimpinan (X1) $\rightarrow$ Kepuasan Kerja & - &
\end{tabular}




\begin{tabular}{lccc}
\hline \multicolumn{1}{c}{ Variabel Laten } & $\begin{array}{c}\text { Pengaruh } \\
\text { Langsung }\end{array}$ & $\begin{array}{c}\text { Pengaruh Tidak } \\
\text { Langsung }\end{array}$ & Pengaruh Total \\
\hline$(\mathrm{Z}) \rightarrow$ Kinerja SWI (Y) & - & 0.222 & \\
Budaya Kerja (X2) $\rightarrow$ Kepuasan Kerja $(\mathrm{Z}) \rightarrow$ & - & $0.177 \times 0.37=$ & $0.177+0.48=0.657$ \\
Kinerja SWI (Y) & - & $0.25 \times 0.37=$ & $0.092+0.41=0.502$ \\
Motivasi Kerja (X3) $\rightarrow$ Kepuasan Kerja (Z) & & 0.092 & \\
$\rightarrow$ Kinerja SWI (Y) & & &
\end{tabular}

Pengaruh total (Tabel 6) Kepemimpinan terhadap Kinerja SWI melalui Kepuasan kerja sebesar 0,822 menjadi lebih besar dibandingkan pengaruh secara langsung Variabel Kepemimpinan terhadap Kinerja SWI sebesar 0.60. Hal ini menunjukan bahwa Kepuasan kerja ternyata mampu memediasi pada kedua variabel tersebut. Pengaruh total Budaya kerja terhadap Kinerja SWI melalui Kepuasan kerja sebesar 0,657 menjadi lebih besar dibandingkan pengaruh secara langsung Budaya kerja terhadap Kinerja SWI sebesar 0.48. Hal ini menunjukkan bahwa Kepuasan kerja ternyata mampu memediasi pada kedua variabel tersebut. Pengaruh total Motivasi Kerja terhadap Kinerja SWI melalui variabel Kepuasan Kerja sebesar 0,502 menjadi lebih besar dibandingkan pengaruh secara langsung Motivasi Kerja terhadap Kinerja SWI sebesar 0.41 . Hal ini menunjukan bahwa Kepuasan Kerja ternyata mampu memediasi pada kedua variabel tersebut.

\section{Pembahasan}

Berdasarkan hasil analisis (1) Kepemimpinan berpengaruh langsung signifikan positif terhadap Kepuasan kerja. Pimpinan Departemen Penyidikan Sektor Jasa Keuangan OJK selalu memberikan ide-ide yang baik dan bersikap ramah serta menyenangkan perasaan pegawai SWI. Perintah yang diberikan tegas dan jelas serta keputusan yang dibuat cukup mampu dijalankan oleh pegawai. Selalu menjalankan fungsi dan tanggungjawab atasan (pemimpin) serta tidak membedakan pegawai. Jadi pemimpin dapat memberikan sesuatu yang positif dalam meningkatkan kepuasan kerja karyawan SWI. Penelitian ini sejalan dengan Choi \& Long, (2014); Mohammed \& Eleswed, (2013); Sakiru et al., (2013).

(2) Kepemimpinan berpengaruh langsung signifikan positif terhadap Kinerja SWI. Pimpinan Departemen Penyidikan Sektor Jasa Keuangan OJK selalu menginformasikan tentang teknis mengerjakan suatu pekerjaan efektif sehingga dapat membangkitkan rasa percaya diri pegawai SWI untuk menyelesaikan tugas. Pemimpin mampu memberikan instruksi dan solusi secara cepat terhadap masalah pekerjaan yang dihadapi pegawai. Oleh sebab itu pemimpin inilah merupakan faktor yang menjadi penentu yang mempengaruhi kinerja pegawai SWI. Penelitian ini sejalan dengan Alberto et al., (2019); Juhary et al., (2019); Gadot, (2007).

(3) Budaya Kerja berpengaruh langsung signifikan positif terhadap Kepuasan kerja. OJK selalu membuka kesempatan memberikan ide kreatif untuk kemajuan perusahaan dan selalu memberikan kesempatan berinisiatif sendiri untuk menyelesaikan pekerjaan dengan baik. Pola membentuk budaya kerja mengacu kepada nilai strategis yaitu integritas dengan bertindak objektif, adil dan konsisten sesui dengan etik dan kebijakan organisasi. Profesionalime bekerja dengan penuh tanggung jawab berdasarkan kompetensi yang tinggi untuk mencapai kinerja terbaik. Sinerji berkolaborasi dengan seluruh pemangku kepentingan baik internal maupun eksternal secara produktif dan berkualitas. Inklusif terbuka dan menerima keberagaman pemangku kepentingan serta memperluas kesempatan dan akses masyarakat terhadap industri keuangan. Visioner memiliki wawasan yang luas dan mampu melihat kedepan (Forward Looking) serta dapat berpikir di luar kebiasaan (Out of The Box Thinking). Para pegawai SWI umumnya bekerja cukup lama sehingga sangat dimungkinkan mereka memiliki tingkat kepuasan yang tinggi. Penelitian ini sejalan dengan Chang \& Lee, (2007); Lok \& Crawford, (2004); Lund, (2003); Sempane et al., (2003). 
(4) Budaya Kerja berpengaruh langsung signifikan positif terhadap Kinerja SWI. Departemen Penyidikan Sektor Jasa Keuangan OJK bagian kegiatan perusahaan tidak hanya menekankan pada output tapi juga proses dan memotivasi berusaha melahirkan usulan baru yang sejalan dengan upaya mengefektifkan operasionalisasi organisasi oleh fungsi yang didukung Struktur tata kelola yang jelas, pelaksanaan tata kelola fungsi asurans yang profesional dan obyektif dengan menggunakan model the three lines of defense (tiga lapis pertahanan) dan strategi combined assurance yang memberikan metode praktis untuk memastikan governance process berjalan secara efektif. Kemudian inisiatif dalam rangka implementasi dan penguatan governance process yaitu dengan program pengendalian gratifikasi, revitalisasi whitle blowing system dan fungsi anti fraud. Budaya kerja yang baik dilakukan berulang-ulang oleh pegawai penyidik jasa keuangan berpengaruh terhadap Kinerja individu maupun kelompok SWI. Penelitian ini sejalan dengan Romadhona \& Wahyuningtyas, (2019); Kawiana et al., (2018); Appealbaoum et al., (2004); Silverthorne, (2004); Lund, (2003).

(5) Motivasi Kerja berpengaruh langsung signifikan positif terhadap Kepuasan. Organisasi yang sukses didukung oleh basis karyawan yang berkomitmen. Pegawai selalu berusahan bekerja keras untuk mencapai prestasi terbaik dalam bekerja dan merasa bangga dengan perusahaan. Ini adalah energi yang mendorong pegawai menuju visi organisasi yaitu menjadi lembaga pengawas industri jasa keuangan yang terpercaya, melindungi kepentingan konsumen dan masyarakat, dan mampu mewujudkan industri jasa keuangan menjadi pilar perekonomian nasional yang berdaya saing global serta dapat memajukan kesejahteraan umum.. Organisasi harus mampu mengidentifikasi dan mengevaluasi motivasi yang diperoleh seorang pegawai agar kepuasan kerja meningkatkannya. Penelitian ini sejalan dengan Waspodo et al., (2017); Kalpana, (2013); Tung et al., (2012); Jeffrey et al., (2011); Singh \& Vivek Tiwari, (2011); Navdeep, (2011); Azash, et al., (2011); Maxime et al., (2009).

(6) Motivasi Kerja berpengaruh langsung signifikan positif terhadap Kinerja SWI.

Visi organisasi agar dapat diwujudkan jika terselenggaranya seluruh kegiatan di dalam sektor jasa keuangan secara teratur, adil, transparan, dan akuntabel, sistem keuangan yang tumbuh secara berkelanjutan dan stabil serta dapat melindungi kepentingan konsumen dan masyarakat. Proses ini dapat dilaksanakan jika perusahaan selalu memberikan penghargaan atas prestasi yang dicapai pegawai SWI. Kompensasi yang diberikan selama ini sudah mampu memenuhi kebutuhan hidup serta adanya pengakuan dan penghargaan saat berhasil melakukan pekerjaan dengan baik. Penelitian ini sejalan dengan (Gachengo \& Susy, (2017); Mougbo, (2013); Ali et al., (2016); Mensah \& Tawiah, (2016); Arianti et al., (2019); Naa (2018); Andico \& Hadi (2013) motivasi kerja berpengaruh terhadap kinerja.

(7) Kepuasan kerja berpengaruh langsung signifikan positif terhadap Kinerja SWI. Umumnya para pegawai SWI melakukan pekerjaan mereka merasa puas. Kompensasi yang diterima setiap bulannya setimpal dengan usaha yang dikeluarkan dalam melakukan pekerjaan yang dibebankan selain itu pegawai merasakan keamanan dalam bekerja, karena pekerjaan ataupun perintah yang diberikan sesuai dengan prosedur yang benar. Oleh karena itu kepuasan pegawai SWI memiliki pengaruh emosi dan komponen kinerja. Penelitian ini sejalan dengan Kim et al., (2017); Garner, (2012); Coombes, (2012); Lawler, (2007).

\section{SIMPULAN}

Penelitian ini dilakukan pada Satgas Waspada Investasi (SWI) Otoritas Jasa Keuangan. Variabel yang diteliti yaitu Kepemimpinan, Budaya Kerja, Motivasi Kerja, Kepuasan Kerja dan Kinerja. Sebanyak 100 responden yang di analisis menggunakan SmartPLS. Hasil penelitian menunjukan bahwa karakteritik responden berjenis kelamin Pria lebih banyak karena dalam dalam proses penyidikan diperlukan kondisi fisik dan waktu yang cukup baik. Usia pegawai 
terbanyak antara 26-45 tahun yang merupakan usia cukup matang dalam memeroses penyidikan. Rata-rata Pegawai SWI cukup berpengalaman melakukan proses penyidikan.

Pimpinan selalu memberikan ide-ide yang baik dan selalu bersikap ramah dan menyenangkan. Perintah yang diberikannya tegas dan jelas serta keputusan yang dibuat mampu dijalankan oleh pegawai. Pemimpin mampu memberikan instruksi dan solusi secara cepat terhadap masalah pekerjaan yang dihadapi. Organisasi selalu membuka kesempatan bagi pegawai dapat memberikan ide kreatif untuk kemajuan. Pola untuk membentuk budaya kerja mengacu kepada nilai strategis yaitu integritas, profesionalime, sinerji, inklusif dan visioner. Perusahaan memotivasi berusaha melahirkan ide-ide baru yang sejalan dengan upaya mengefektifkan operasionalisasi organisasi oleh fungsi yang didukung Struktur tata kelola yang jelas, pelaksanaan tata kelola fungsi asurans yang profesional dan obyektif dengan menggunakan model the three lines of defense (tiga lapis pertahanan) dan strategi combined assurance yang memberikan metode praktis untuk memastikan governance process berjalan secara efektif. Inisiatif dalam rangka implementasi dan penguatan governance process yaitu program pengendalian gratifikasi, revitalisasi whitle blowing system dan fungsi anti fraud. Budaya kerja penyidik jasa keuangan dilakukan berulang-ulang oleh pegawai berpengaruh terhadap Kinerja individu maupun kelompok SWI. Pegawai selalu berusahan bekerja keras untuk mencapai prestasi terbaik dalam bekerja dan merasa bangga dengan perusahaan. Ini adalah energi yang mendorong pegawai menuju visi organisasi. Agar dapat diwujudkan terselenggaranya seluruh kegiatan secara teratur, adil, transparan, dan akuntabel. Umumnya para pegawai SWI melakukan pekerjaan mereka merasa puas. Kompensasi yang diterima setiap bulannya setimpal dengan usaha yang dikeluarkan dalam melakukan pekerjaan yang dibebankan selain itu pegawai merasakan keamanan dalam bekerja, karena pekerjaan ataupun perintah yang diberikan sesuai dengan prosedur yang benar

\section{REFERENSI}

Ali, Amjad, Li Zhong Bin, Huang Jian Piang, ZulfiqarAli. (2016). The Impact of Motivation on the Employee Performance and Job Satisfaction in IT Park (Software House) Sector of Peshawar, Pakistan. International Journal of Academic Research in Business and Social Sciences, 6(9), 297-310. http://dx.doi.org/10.6007/IJARBSS/v6-i9/2311

Agho, A.O., Mueller, C.W. \& Price, J.L. (1993) Determinants of Employee Job Satisfaction: An Empirical Test of a Causal Model. Human Relations, 46, 1007-1027. http://dx.doi.org/10.1177/001872679304600806

Agung, Dwi Nugroho Arianto. (2013). Pengaruh Kedisiplinan, Lingkungan Kerja Dan Budaya Kerja Terhadap Kinerja Tenaga Pengajar. Jurnal Economia, 9(2), 191-200.

DOI: https://doi.org/10.21831/economia.v9i2.1809

Ahmad, S. D. (2018). Peranan Otoritas Jasa Keuangan dalam Penanggulangan Investasi Ilegal di Indonesia. Jurnal Privat Law, 6(1), 1-12.

Ajis, M. R. P., Hidayati, T., \& Trichayadinata, I. (2020). Kepuasan Kerja Terhadap Sikap Kerja, Komitmen Organisasi, serta Kinerja Karyawan Platinum Hotel dan Convention Hall Balikpapan. Jurnal Ilmu Manajemen Mulawarman (JIMM), 4(2). DOI: http://dx.doi.org/10.29264/jimm.v4i2.4103

Alberto, J., Amar, S., \& Patrisia, D. (2019, April). The Influence of Leadership, Organizational Culture and Work Climate on Employee Performance in the Department of Public Works and Spatial Planning of Padang City. In 2nd Padang International Conference on Education, Economics, Business and Accounting (PICEEBA-2 2018). Atlantis Press. DOI: https://doi.org/10.2991/piceeba2-18.2019.82 
Altmäe, S.; Türk, K.; Toomet, O. (2013). Thomas-Kilmann's Conflict Management Modes and their Relationship to Fiedler's Leadership Styles (basing on Estonian organizations). Baltic Journal of Management, 8 (1), 45-65. Doi:http://dx.doi.org/10.1108/17465261311291650

Andico, C., \& Hadi, S. P. (2013). Pengaruh Kompensasi dan Motivasi Kerja Terhadap Kinerja Karyawan PT. Pelabuhan Indonesia III (Persero) Terminal Peti Kemas Semarang. Jurnal Ilmu Administrasi Bisnis. 2(4), 146-154.

Appelbaum, S., Bartolomucci, N., Beaumier, E., Boulanger, J., Corrigan, R., Dore, I., Girard, C., \& Serroni, C. (2004). Organizational citizenship behavior: A case study of culture, leadership and rust. Management Decision, 42(1), 13-40.

Ardhani, J., \& Ratnasari, S. L. (2019). Pengaruh Motivasi Kerja Terhadap Kinerja Pegawai PT PLN Batam. Jurnal Dimensi, 8(2),372-385.

Azash, S.Md, Ramesh Safare, M.Sudheer Kumar (2011). The motivational factors and job satisfaction: a Study on selected public and private sector bank Employees in Kadapa district, Andhra Pradesh. International Refereed Research Journal, Journal of Arts, Science \& Commerce II(4), 161.

Bapepam-LK Nomor Kep-208/BL/2007 tanggal 20 Juni 2007

Bass, B.M. (1999). Two decades of research and development in transformational leadership. European Journal of Work and Organizational Psychology, 8(1), 9-32. https://doi.org/10.1080/135943299398410

Chang, S. \& Lee, M. S. (2007). A study on the relationship among leadership, organizational culture, the operation of learning organization and employees' job satisfaction. Learning Organization, 14(02), 155-185.

Choi Sang Long, Lee Yean Thean, Tan Owee Kowang. (2013). The Transformational Leadership: A Possible TQM Solution to Increase Job Satisfaction? Life Sci J, 10(4):14741484

Choi- Sang Long, Wan Mardhia M. Yusof, Tan Owee Kowang \& Low Hock Heng 1 (2014). The Impact of Transformational Leadership Style on Job Satisfaction. World Applied Sciences Journal, 29 (1), 117-124. DOI: 10.5829/idosi.wasj.2014.29.01.1521

Coombes, J. (2012). Positive effects of rewards and performance standards on intrinsic motivation. The Psychological Record, 53(4), 4-10

Egan, T. M., Yang, B., \& Bartlett, K. R. (2004). The effects of organizational learning culture and job satisfaction on motivation to transfer learning and turnover intention. Human Resource Development Quarterly, 15(3), 279-301. doi:10.1002/hrdq.1104

Farooqui, M. S., \& Nagendra, A. (2014). The impact of person organization fit on job satisfaction and performance of the employees. Procedia economics and Finance, 11, 122129. DOI: $10.1016 / \mathrm{S} 2212-5671(14) 00182-8$

Fred C. Lunenburg, (2011). Motivating by Enriching Jobs to Make Them More Interesting and Challenging International Journal Of Management, Business, And Administration, 15(1), 1-11

Gachengo, Virginiah \& Susy Wekesa. (2017). Influence of motivation on employee performance: a case of national bank of Kenya. Int. J. Bus. Manag. Soc. Res. 03(02): 179185 https://doi.org/10.18801/ijbmsr.030217.20

Gadot, E. V. (2007). Leadership style, organizational politics, and employees' performance: An empirical examination of two competing models. leadership style, 36 (5), 661-683. DOI 10.1108/00483480710773981

Garner, E. (2012). Training skills: How to improve the skills and performnace of your employees. Ventus: Eric Garner \& Ventus Publishing ApS. Available at: http://www.bookboon.com / 
Ghazi Ben Saad \& Muzaffar Abbas (2018). The impact of organizational culture on job performance: a study of Saudi Arabian public sector work culture. Problems and Perspectives in Management, 16(3), 207-218. doi:10.21511/ppm.16(3).2018.17

Goris. J. R. (2006). Effect of satisfaction with communication on the relationship between individual job satisfaction congruence and job performance satisfaction. Journal of Management Development, 33(1), 64-96

Hair, JF, WC Black, BJ Babin, RE Anderson, RL Tatham. (2014). Multivariate Data Analysis. New International Edition., New Jersey: Pearson.

Heskett, J. L. (2012). The culture cycle: how to shape the unseen force that transforms performance. Upper Saddle River, N.J., FT Press.

Hsiao, J. M., \& Chen, Y. C. (2012). Antecedents and consequences of job satisfaction: A case of automobile component manufacturer in Taiwan. Journal of Organizational Innovation, 5 (2), 164-178.

https://www.ojk.go.id/id/kanal/perbankan/data-dan-statistik/booklet-perbankanindonesia/Pages/Booklet-Perbankan-Indonesia-2017.aspx, diunduh 25 Maret 2020

https://www.ojk.go.id/id/kanal/perbankan/data-dan-statistik/booklet-perbankanindonesia/Pages/Booklet-Perbankan-Indonesia-2017.aspx (Diunduh, 12 Januari 2020)

https://www.ojk.go.id/waspada-investasi/id/berita/Pages/OJK-Perkuat-Satgas-WaspadaInvestasi.aspx

Inuwa M. (2016). Job Satisfaction and Employee Performance: An Empirical Approach. The Millennium University Journal, 1(1): 90-103.

Jalal R. M. Hanaysha, Khawaja Khalid, Nik Kamariah Nik Mat, Fosa Sarassina, Muhd Yahya Bin Ab Rahman, Ahmad Sazali Bin Zakaria. (2012). Transformational Leadership and Job Satisfaction. American Journal of Economics 2 (Special Issue): 145148. DOI: $10.5923 /$ j.economics.20120001.32

Jeffrey L. Herman, Jennifer J. Deal, Jamie Lopez, William A. Gentry, Stephanie Shively, Marian Ruderman, Lori Zukin. (2011). Motivated by the Organization's Mission or Their Career? Implications for Leaders in Turbulent Times, Center for Creative Leadership.

Juhary, A., Mardiyana, N., \& Owin Jamasy, D. (2019). The Effect Of Transformational And Transactional Leadership On The Commitment Of Organization, Turnover, And Perfomance (At Baitul Maal Wat Tamwil, The Special Region Of Yogyakarta). IOSR Journal of Business and Management (IOSR-JBM), 21(3), 9-17. DOI: 10.9790/487X2103040917

Kalpana Rathore Solanki (2013). Flextime Association with Job Satisfaction, Work Productivity, Motivation \& Employees Stress Levels. Journal of Human Resource Management. 1(1), 9-14. doi: 10.11648/j.jhrm.20130101.12

Kawiana, I. G. P., Dewi, L. K. C., Martini, L. K. B., \& Suardana, I. B. R. (2018). The influence of organizational culture, employee satisfaction, personality, and organizational commitment towards employee performance. International Research Journal of Management, IT and Social Sciences, 5(3), 35-45. Retrieved from https://sloap.org/journals/index.php/irjmis/article/view/166

Kazan, Halim, Özer, Gökhan, Ayse Tansel Çetin. (2006). The effect of manufacturing strategies on financial performance. Measuring Business Excellence, 10(1), 14-26

Khuzaeni, MS. Idrus, Djumahir, Solimun. (2013). The Influence of Work Culture, Work Stress to the Job Satisfaction and Employees Performance in the State Treasury Service Office in Jakarta, Indonesia. Journal of Business and Management (IOSR-JBM). 9(2), 49-54

Kim, W. H., Ra, Y. A., Park, J. G., \& Kwon, B. (2017). Role of burnout on job level, job satisfaction, and task performance. Leadership and Organization Development Journal, 38(5), 630-645. https://doi.org/10.1108/LODJ-11-2015-0249 
Kotter, J. (2012). Corporate culture and performance. New York: Free press.

Kurniawan, D. A. (2019). Pengaruh Kepemimpinan dan Motivasi Kerja terhadap Kinerja Karyawan (Di Cemara Motor Main Dealer Honda Leles Garut). Journal of Knowledge Management, 12(01), 1-11.

Latief, A., Syardiansah, S., \& Safwan, M. (2019). Pengaruh Komitmen Organisasi dan Kepuasan Kerja terhadap Kinerja Karyawan Badan Penyelenggara Jaminan Sosial Kesehatan. Jurnal Administrasi Publik (Public Administration Journal), 9(1), 43-48. DOI: https://doi.org/10.31289/jap.v9i1.2256

Lawler, E. (2007). Job design and employee motivation. Personality Psychology, 22(4), 426435. https://doi.org/10.1111/j.1744-6570.1969.tb00343.x

Lok, P., \& Crawford, J. (2004). The effect of organisational culture and leadership style on job satisfaction and organisational commitment: A cross-national comparison. Journal of Management Development, 23(4), 321-338. https://doi.org/10.1108/02621710410529785

Lund, D. B. (2003). Organizational culture and job satisfaction. Journal of Business \& Industrial Marketing, 18(3), 219-236. doi: 10.1108/0885862031047313

MacIntosh, E. W., \& Doherty, A. (2010). The influence of organizational culture on job satisfaction and intention to leave. Sport Management Review, 13(2), 106-117. doi:10.1016/j.smr.2009.04.006

Maxime A. Tremblay, Ce'line M. Blanchard,, Sara Taylor, and Luc G. Pelletier, Martin Villeneuve, (2009). Work Extrinsic and Intrinsic Motivation Scale: Its Value for Organizational Psychology Research, Canadian Journal of Behavioural Science , 41(4), 213-226. DOI: 10.1037/a0015167

Mensah, Elizabeth Boye Kuranchie \& Kwesi Amponsah-Tawiah. (2013). Employee Motivation and Work Performance: A Comparative. Journal of Industrial Engineering and Management (JIEM), 9(2), 255-309 http://dx.doi.org/10.3926/jiem.1530

Mintzberg, H. (2010). Developing Leaders? Developing Countries? Oxford Leadership Journal , $1(2), 1-10$

Mohammad, M. S. (2012). Transformational Leadership and Employees Job Satisfaction and Commitment: A Structural Equation Investigation. Journal of American Science, 8 (7), 11 19.

Mohammed, F., \& Eleswed, M. (2013). Job Satisfaction and Organizational Commitment: A Correlational Study in Bahrain. International Journal of Business, Humanities and Technology, 3 (5), 43-53.

Monecke, A. \& Leisch, F. (2012). semPLS: structural equation modeling using partial least squares. Journal of Statistical Software, 48 (3), 1-32

Muogbo, Uju S. (2013). The Influence of Motivation on Employees' Performance: A Study of Some Selected Firms in Anambra State. An International Journal of Arts and Humanities Bahir Dar, 2 (3), 134-151

Mustanir, A., \& Rusdi, M. (2019). Participatory Rural Appraisal (PRA) Sebagai Sarana Dakwah Muhammadiyah Pada Perencanaan Pembangunan Di Kabupaten Sidenreng Rappang. Prosiding: Konferensi Nasional Ke-8 Asosiasi Program Pascasarjana Perguruan Tinggi Muhammadiyah Aisyiyah (APPPTMA). Tantangan Pascasarjana di Era Revolusi Industri 4.0At: Medan

Naa, A. (2018). Pengaruh Lingkungan Kerja, Motivasi Kerja Dan pelatihan Terhadap Kinerja Pegawai Di Kantordistrik Bintuni Kabupaten Teluk Bintuni. Jurnal Renaissance, 2(2), 167-176.

Nabi, Md. Nurun, Md. Monirul Islam, Tanvir Mahady Dip, \& d. Abdullah Al Hossain. (2017). The Impact of Motivation On Employee Performances: A Case Study Of Karmasangsthan 
Bank Limited, Bangladesh. International Journal of Business and Management Review, 5(4), 57-78.

Navdeep Kumar \& Pankaj Garg, (2011). Impact of motivational factors on employee's job satisfaction- A study on some selected organization in Punjab, India, Asian Journal Of Management Research 672(2), 672-683.

Nazwirman. (2020). Keterampilan Kepemimpinan Bisnis Global Yang Efektif. Journal Management, Business, and Accounting, 19(1), 49-65. https://doi.org/10.33557/mbia.v19i1.502

Nikos Kakkos, Panagiotis Trivellas, Kaliopi Fillipou, (2010). Exploring the link between job motivation, work stress and job satisfaction, Evidence from the banking industry. 7th International Conference on Enterprise Systems, Accounting and Logistics (7th ICESAL 2010), Rhodes, Greece, 211-230

Northouse, P.G. (2007). Leadership: Theory and practice. 4th ed. Sage: Thousand Oaks, CA

Nugraha. Ubaidillah. (2018). Strategy to Accelerate Financial Literacy Rate in Indonesia: Best Practices from Selected Countries. The Indonesian Journal of Development Planning 2(1), 78-86. https://doi.org/10.36574/jpp.v2i1.33

Permanasari, E. Y. (2019). Pengaruh Motivasi Kerja, Kompetensi dan Kompensasi Terhadap Kinerja Karyawan (Studi pada Kantor Notaris di Kediri). REVITALISASI Jurnal Ilmu Namajemen, 6(1), 68-79.

Rahman, Md Habibur, Mst. Rinu Fatema, \& d. Hazrat Ali, (2019). Impact of Motivation and Job Satisfaction on Employee's Performance: An Empirical Study. Asian Journal of Economics Business and Accounting, 10(4), 1-10. DOI: 10.9734/ajeba/2019/v10i430112

Rajendar, K..Garg \& Jun Ma (2005). Benchmarking Culture and Performance in Chinese Organizations. Benchmarking an International Journal, 12(3):260-274. DOI: $10.1108 / 14635770510600375$

Robescu, Ofelia \& Alina-Georgiana Iancu. (2016). The Effects of Motivation on Employees Performance in Organizations. Valahian Journal of Economic Studies. 0(0),1-8. DOI: 10.1515/vjes-2016-0006

Romadhona, A. F., \& Wahyuningtyas, R. (2019). Komitmen dan Budaya Organisasi Terhadap Kinerja Karyawan Bank BJB Cabang Tamansari. Jurnal Riset Bisnis dan Manajemen, 12(1), 24-30. DOI: http://dx.doi.org/10.23969/jrbm.v12i1.1523

Saari, L.M. \& Judge, T.A., (2004). Employee attitudes and job satisfaction. Human Resource Management: Published in Cooperation with the School of Business Administration, The University of Michigan and in alliance with the Society of Human Resources Management, 43(4), 395-407. https://doi.org/10.1002/hrm.20032

Sakiru, O., D'Silva, J., Othman, J., DaudSilong, A., \& Busayo, A. (2013). Leadership Styles and Job Satisfaction among Employees in Small and Medium Enterprises. International Journal of Business and Management; 8(1)3, 34-41. DOI:10.5539/ijbm.v8n13p34

Samosir, J. H. P.\& Pujiono. (2018). Peranan Otoritas Jasa Keuangan dalam Memberikan Perlindungan Hukum Terhadap Korban Investasi Ilegal. Jurnal Privat Law. 6(2), 237-242.

Santos, Joaquim Pacheco, AntónioCaetano, \& Susana M.Tavares. (2015). Is training leaders in functional leadership a useful tool for improving the performance of leadership functions and team effectiveness?. The Leadership Quarterly. 26(3), 470-484. https://doi.org/10.1016/j.leaqua.2015.02.010

Schein, Edgar H. (2014). Organizational Culture and Leadership. San Francisco: Josey-Bass Publishers.

Sempane M., Rieger, H.S., Roodt, G. (2003). Job satisfaction in relation to organizational culture. SA Journal of Industrial Psychology, 28(2), 23-30. DOI: https://doi.org/10.4102/sajip.v28i2.49 
Silverthorne, C. (2004). The impact of organizational culture and person-organization fit on organizational commitment and job satisfaction in Taiwan. Leadership \& Organization Development Journal, 25(7), 592-599. doi:10.1108/01437730410561477

Singh, S. K. \& Vivek Tiwari. (2011). Relationship between motivation and job satisfaction of the white collar employees: a case study, SMS Varanasi, VII(2), 31-39.

Sinha, Smrita, Ajay Kumar Singh, NC Gupta, Rajul Dutt. (2010). Impact of Work Culture on Motivation and Performance Level of Employees in Private Sector Companies. Acta Oeconomica Pragensia, (6):49-67. DOI: 10.18267/j.aop.321

Sofyan, S., Jabbar, A., \& Sunarti, S. (2019). Pengaruh Budaya Kerja Terhadap Budaya Kerja Pengaruh Budaya Kerja Terhadap Kedisiplinan Pegawai di Kantor Desa Bina Baru Kecamatan Kulo Kabupaten Sidenreng Rappang. Moderat: Jurnal Ilmiah Ilmu Pemerintahan, 5(1), 56-69.

Sunny, A. G., Suryana, Y., Sumantri, S., \& Soemaryani, I. (2019, May). Organizational Culture, Leadership, Organizational Commitment and Work Engagement of Local Government Employees. In Proceeding Interuniversity Forum for Strengthening Academic Competency. 1(1),384-391.

Susita Asree, Mohamed Zain \& Mohd Rizal Razalli. (2010). Influence of leadership competency and organizational culture on responsiveness and performance of firms. International Journal of Contemporary Hospitality Management. 22(4), 500 - 516. DOI: $10.1108 / 09596111011042712$

Svensson. (2005). Leadership performance in TQM: a contingency approach, The TQM Magazine. 17 (6), 527-536. DOI: 10.1108/09544780510627624

Tung-Liang Chen, Ming -Yi Huang, Tchiu-Hui Su. (2012). Work Motivation, Work Stress, and Job Satisfaction in between Taiwan and China - An Empirical Study. World Academy of Science, Engineering and Technology. International Journal of Psychological and Behavioral Sciences, 6(8), 2256-2260

Uzonna, Rex. (2013). Impact of motivation on employees performance: A case study of CreditWest Bank Cyprus. Journal of Economics and International Finance, 5(5):199-211. DOI: $10.5897 / \mathrm{JEIF} 12.086$

Vance, R. J. (2006). Employee Motivation and Commitment: A Guide to Understanding Measuring and Increasing Engagement In your Organization. Alexandria, A: SHRM Foundation

Waspodo, A. A., Dharmawan, R., \& Handaru, A. W. (2017). The Influence of Compensation, Motivation, and Career Development on Employees Job Satisfaction at PT Nikko Cahaya Electric. JRMSI-Jurnal Riset Manajemen Sains Indonesia.8(1), 58-83. DOI: https://doi.org/10.21009/JRMSI.008.1.04

Yukl, Gary. (2013). Leadership In Organizations. Pearson

Zigarmi, D., \& Roberts, T. P. (2017). A test of three basic assumptions of Situational Leadership II Model and their implications for HRD practitioners. European Journal of Training and Development. 41(3), 241-260. DOI: 10.1108/EJTD-05-2016-0035. 